\title{
EFFECTS OF SOLIDIFICATION TIME ON MECHANICAL PROPERTIES AND WEAR BEHAVIOUR OF SAND CAST ALUMINIUM ALLOY
}

\author{
S. Ilangovan \\ Assistant Professor (SG), Department of Mechanical Engineering, Amrita School of Engineering, Amrita Vishwa \\ Vidyapeetham, Ettimadai Post, Coimbatore - 641105, Tamil Nadu, India.
}

\begin{abstract}
An investigation was carried out to understand the effects of solidification time of the cylindrical specimen on hardness, wear rate and the coefficient of friction of Aluminium alloy (LM4). The commercially available LM4 Aluminium alloy was melted in a crucible furnace under argon atmosphere. The molten metal was poured into sand moulds having dissimilar size holes. The cast rods were tested for Vickers micro-hardness, wear rate and the coefficient of friction. The solidification time increases from 0.22 to 0.61 seconds when the diameter varied from 20 to $35 \mathrm{~mm}$. It was found that the hardness of the alloy vary with the diameter of the rod. Wear rate is inversely proportional to the hardness of the alloy. It was observed that the yield strength and tensile strength are increases with hardness, whereas the \% elongation decreases. Further, the coefficient of friction is independent of hardness and not affected by the sliding time. Wear rate decreases linearly with hardness.
\end{abstract}

Keywords: LM4- alloy, coefficient of friction, wear rate, solidification time, sand cast. - ****

\section{INTRODUCTION}

The surface-to-volume ratio is an significant quantity in thermal physics. It governs the behaviour of heating/cooling of physical substance as a function of size. The solidification time is a function of the volume of a casting and its surface area [1]. Chvorinov's Rule is a mathematical relationship first expressed by Nicolas Chvorinov in 1940, that relates the solidification time for a simple casting to the volume and surface area of the casting. In simple terms the rule establishes that under otherwise identical conditions, the casting with large surface area and small volume will cool more rapidly than a casting with small surface area and a large volume [2]. Cooling rate can be an indication of material quality. Areas of the casting that cool rapidly generally have a more favorable grain structure and therefore tend to have better mechanical properties. The areas of the casting that cool more slowly generally tend to have poorer material properties $[3,4]$. Therefore, it is responsible of the foundry engineer to control the solidification time to the best of skill so that the microstructure of the final product can be controlled to optimize the properties desired.

In this work, the mechanical properties and the wear behaviour of the Aluminium alloy was studied by varying the solidification time using dissimilar component diameters in sand casting process.

\section{EXPERIMENTAL PROCEDURE}

\subsection{Material Preparation}

The Aluminium alloy (LM4) castings were produced from commercially available LM4 Aluminium billets as shown in Figure1. The billets were melted in a graphite crucible using an electric furnace. Inert gas such as argon is used to prevent oxidation of the molten metal. The molten metal is poured at a temperature of $720^{\circ} \mathrm{C}$ into the sand moulds at room temperature to make rods of $\varnothing 20, \varnothing 25, \varnothing 30$ and $\varnothing 35$ diameters and length of $150 \mathrm{~mm}$. The photographic image of the cast rods is shown in Figure 2. The chemical composition of the cast alloy was tested using spectrometer and the results are reported in Table 1.

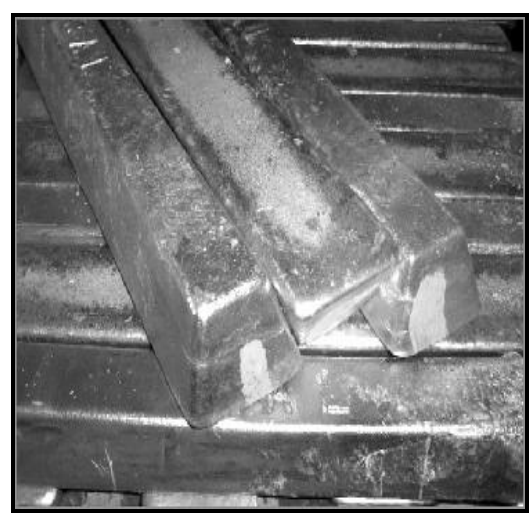

Fig-1: LM4 Aluminium billet 


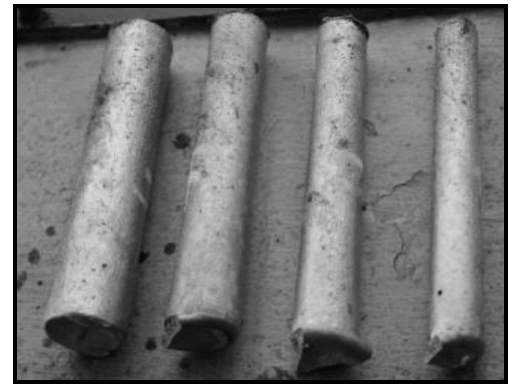

Fig-2: LM4 Aluminium cast rods

Table-1: Alloy composition

\begin{tabular}{|l|l|l|l|}
\hline Al & $\mathrm{Si}$ & $\mathrm{Cu}$ & $\begin{array}{l}\text { Other } \\
\text { Elements }\end{array}$ \\
\hline 91.41 & 5.11 & 2.57 & Balance \\
\hline
\end{tabular}

\subsection{Hardness Testing}

To assess the effect of diameter, the hardness of the entire specimens were measured using a micro-hardness tester (Figure 3). A number of readings were taken at different location for each specimen and an average value was calculated. The specimens were prepared and tested as per ASTM- E384 standard. The parameters used in this test were: $50 \mathrm{gm}-\mathrm{f}$ applied load and $20 \mathrm{~s}$ duration. The hardness values varied in each sample was within $\pm 5 \mathrm{HV}$.

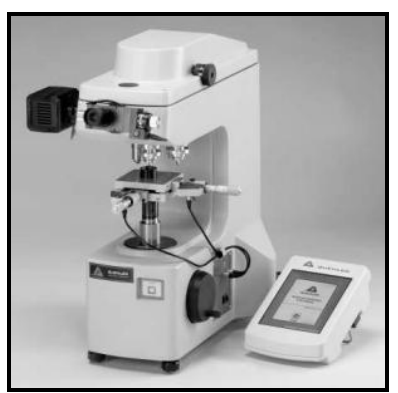

Fig-3: Micro-hardness tester

\subsection{Tensile Testing}

The tensile test was conducted to predict the yield strength (YS), tensile strength (TS) of the material as well as to find the ductility in terms of $\%$ elongation of the alloy. The test specimens were prepared according to ASTM - E4 standard. Figure 4 and 5 shows the drawing and the photographic image of the specimen.

The specimens were tested using computerized universal testing machine (Make: Tinius Olsen; Model: H25KT). The experimental setup is as shown in the Figure 6.

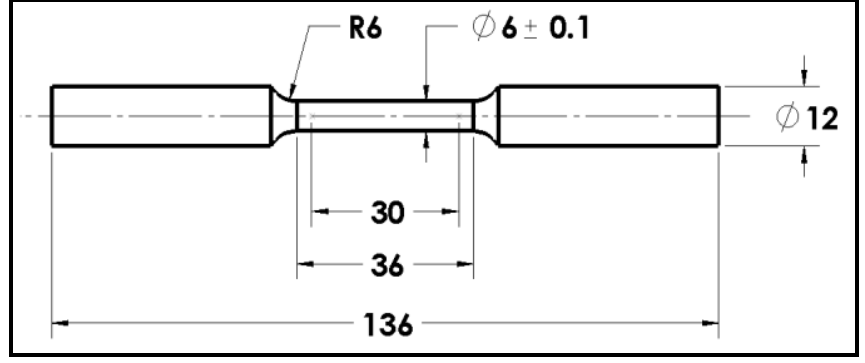

Fig-4: Drawing of the tensile test specimen

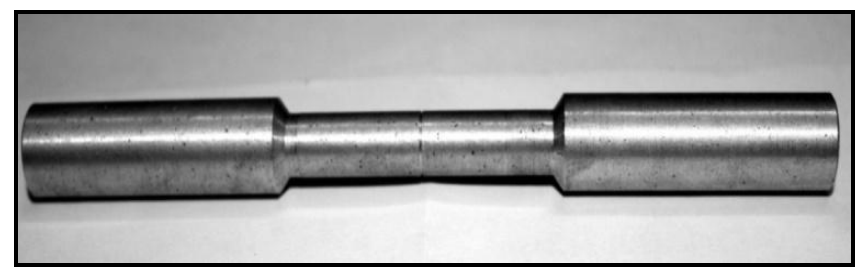

Fig-5: Photograph image of the tensile test specimen

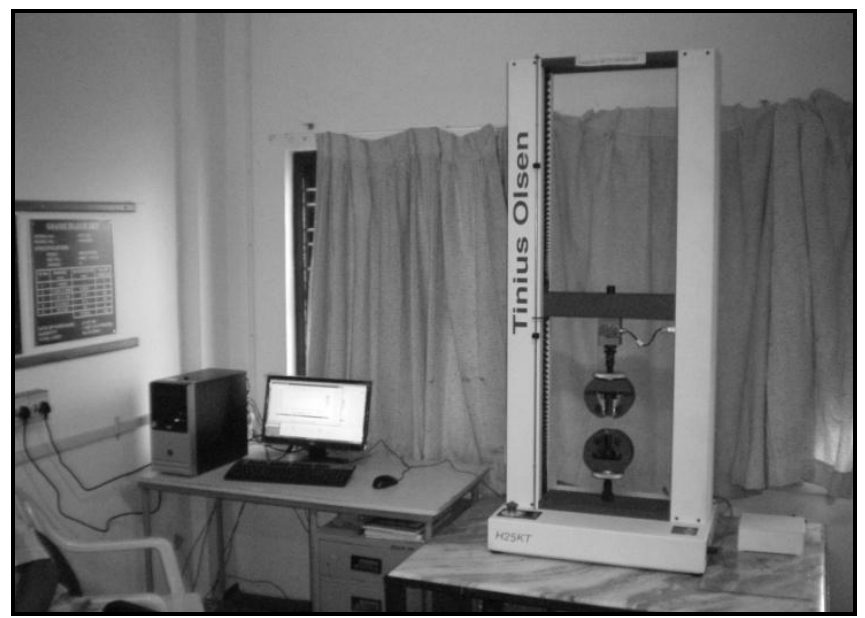

Fig-6: Universal Tensile Testing Machine

\subsection{Friction and Wear Testing}

The friction and wear tests were performed on specimen of all diameters. Pin-on-Disc wear tester was used. It is equipped with LVDT sensors attendant with data acquisition software (Make: Ducom; Model: TR-20LE). The experiment was conducted in dry sliding condition in normal atmosphere. The test specimens in the form of pin of $5 \mathrm{~mm}$ diameter and 40 $\mathrm{mm}$ length were prepared by machining the cast rods. The counter face disc material was hardened steel (EN31). The data acquisition system provides three kinds of plots: (a) Height loss versus time (b) Coefficient of friction versus time and (c) Frictional force versus time. ASTM G99 standard test method was used to conduct the test. The experimental setup is shown in the Figure 7. The wear rate was measured from the volume loss per unit sliding distance. It is expressed in $\mathrm{mm} 3 / \mathrm{m}$. Volume loss was calculated using the plot, height 
loss versus time. The test parameters used for the friction and wear test are shown in Table 2.

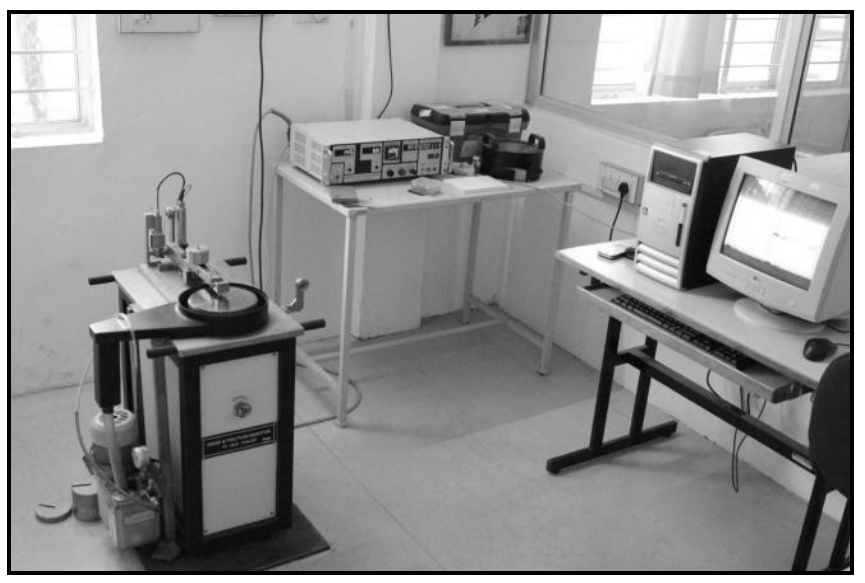

Fig-7: Friction and wear testing setup

Table-2: Friction and wear testing parameters

\begin{tabular}{|l|l|l|}
\hline Test parameters & Unit & Test values \\
\hline Speed & $\mathrm{rpm}$ & 239 \\
\hline Velocity & $\mathrm{m} / \mathrm{s}$ & 1 \\
\hline Track radius & $\mathrm{mm}$ & 40 \\
\hline Time & $\mathrm{s}$ & 600 \\
\hline Load applied & $\mathrm{N}$ & 15 \\
\hline
\end{tabular}

\section{RESULTS AND DISCUSSION}

\subsection{Solidification Time}

The solidification time for each specimen is estimated by using Chvorinov's Rule, which states that the solidification of a casting is directly proportional to the square of the volumeto-surface area of the casting $\left(\mathrm{t}=\mathrm{B}(\mathrm{V} / \mathrm{A})^{\mathrm{n}}\right)$ and the values are reported in Table 3 . The mould constant $\mathrm{B}$, is assumed as $0.1 \mathrm{~s} / \mathrm{mm} 2$. It is noted from the table that the solidification time of the casting increases with increase in diameter of the casting.

Table- 3: Shows the solidification time for various diameters of the specimen

\begin{tabular}{|l|l|l|l|l|}
\hline $\begin{array}{l}\text { Dia. } \\
(\mathrm{mm})\end{array}$ & $\begin{array}{l}\text { Vol. (V) } \\
\left(\mathrm{mm}^{3}\right)\end{array}$ & $\begin{array}{l}\text { Area } \\
(\mathrm{SA}) \\
\left(\mathrm{mm}^{2}\right)\end{array}$ & $\begin{array}{l}(\mathrm{V} / \mathrm{SA})^{2} \\
\left(\mathrm{~mm}^{2}\right)\end{array}$ & $\begin{array}{l}\text { Time, } \\
\mathrm{B}(\mathrm{V} / \mathrm{SA})^{2} \\
\text { in Sec. }\end{array}$ \\
\hline 20 & 47,143 & 10,057 & 22.09 & 0.22 \\
\hline
\end{tabular}

\begin{tabular}{|l|l|l|l|l|}
\hline 25 & 73,661 & 12,768 & 33.64 & 0.34 \\
\hline 30 & $1,06,071$ & 15,557 & 46.24 & 0.46 \\
\hline 35 & $1,44,375$ & 18,425 & 60.84 & 0.61 \\
\hline
\end{tabular}

\subsection{Hardness}

The influence of diameter on hardness of the cast rod is shown in Figure 8. The hardness of the specimen decreases from 94 to $87 \mathrm{HV}$ when the diameter of the specimen increases from 20 to $35 \mathrm{~mm}$. The decrease in the hardness is owing to difference in solidification time $(0.61-0.22=0.39 \mathrm{~s})$.

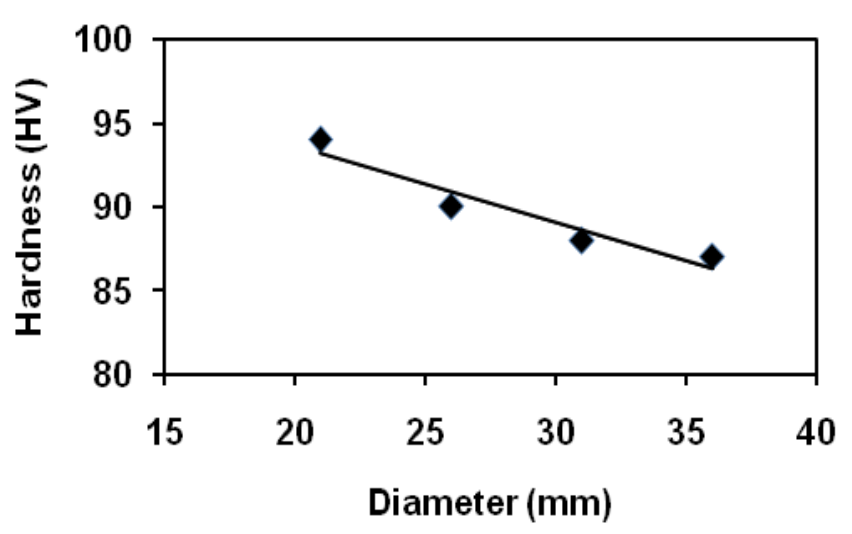

Fig-8: Hardness versus diameter

Figure 9 shows the variation of YS and TS of the alloy with hardness measured at various diameters. Both YS and TS are increasing with hardness of the alloy. Similarly the variation of the \% elongation of the alloy with hardness is shown in the figure. It is noted from the figure that \% elongation decreases with hardness of the alloy. Hence, it may be concluded that the YS and TS and \% elongation are the functions of hardness of the alloy. The behaviour observed in this study is consistent with that of Schwartz and Plews [5].

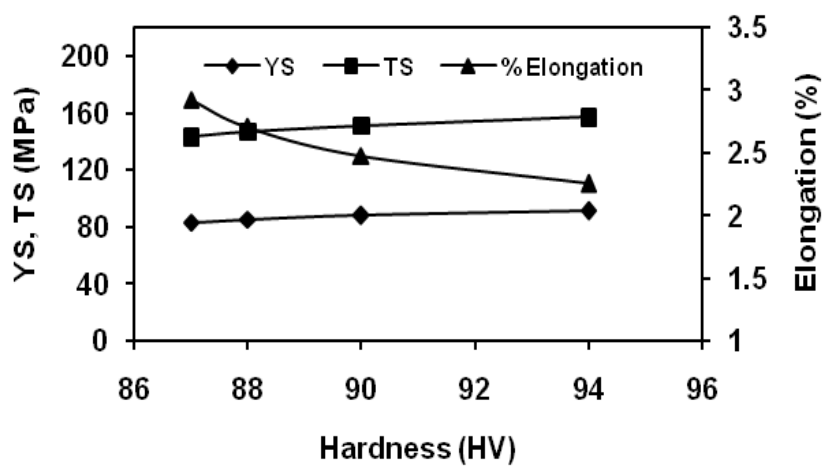

Fig-9: YS, TS, and \%elongation versus hardness 


\subsection{Wear Behavior}

A typical height loss versus sliding time plot for velocity $1 \mathrm{~m} / \mathrm{s}$ at constant load of $15 \mathrm{~N}$ is shown in the Figure 10. It can be seen that the height loss increases linearly with the sliding time. This behavior is in agreement with that of Singh et al. [6].

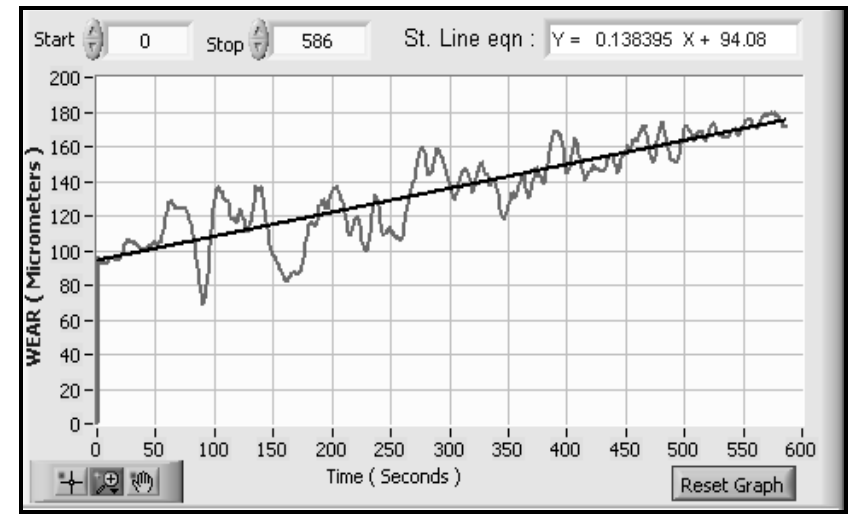

Fig-10: Wear versus time

Figure 11 shows the relationship between wear rate and the hardness of the alloy. The wear rate decreases as the hardness of the alloy increases. It is in agreement with that of Archard's adhesion theory of wear as given in equation 1 [7].

$$
\mathrm{W}_{\mathrm{R}}=\mathrm{k} \times \mathrm{W} / \mathrm{H}
$$

Where, $\mathrm{W}_{\mathrm{R}}=$ wear rate in $\mathrm{mm} 3 / \mathrm{m}$; $\mathrm{k}=$ wear coefficient; $\mathrm{W}=$ applied load in $\mathrm{N}$; $\mathrm{H}=$ hardness in $\mathrm{N} / \mathrm{mm} 2$.

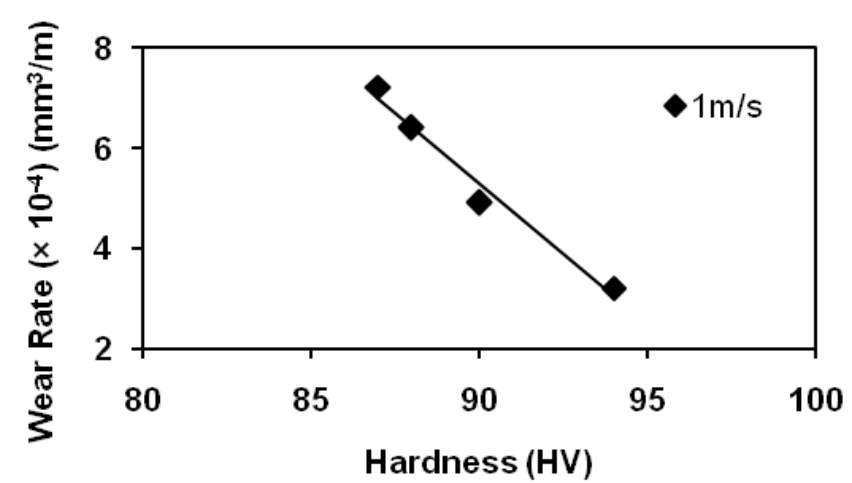

Fig-11: Wear rate versus hardness

A typical plot of coefficient of friction of the alloy as a function of sliding time is shown in the Figure 12. It can be seen from the plot that the coefficient of friction of the alloy reaches a steady state after showing a sharp increase during the initial sliding period. The sharp increase is due to uneven contact between specimen pin and the counterpart disc. Once an ideal contact is achieved, then the result shows the steady state value. The values of coefficient of friction obtained in the steady state regime remains nearly constant ( 0.4) for sliding time. Hence, we may conclude that the coefficient of friction of the alloy is not affected by the sliding time of the alloy.

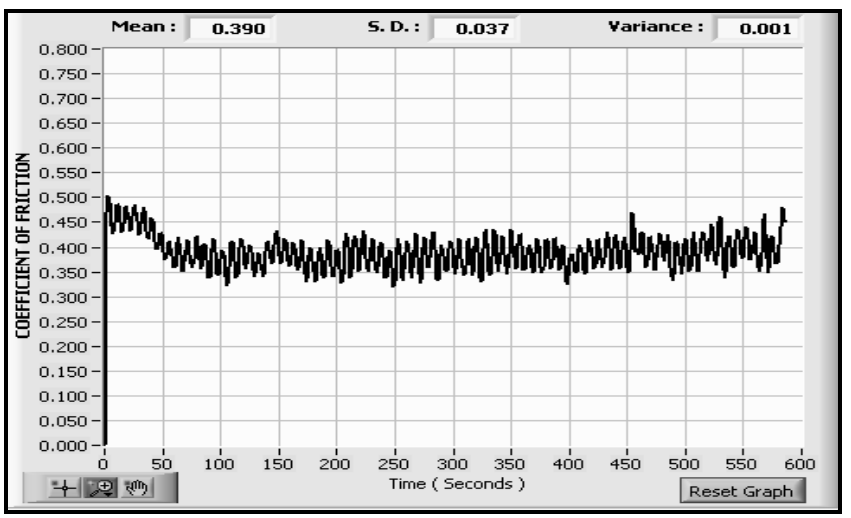

Fig-12: Coefficient of friction versus sliding time

Figure 13 shows the variation of COF with hardness of the alloy. The value of COF is found to be around 0.4 with marginal variation. Hardness of the alloy does not affect the COF value. Hence, we may conclude from the results that COF value is not affected by the hardness of the alloy. An observation of this study is in agreement with that of Zhang et al. [8, 9] and Singh et al. [6].

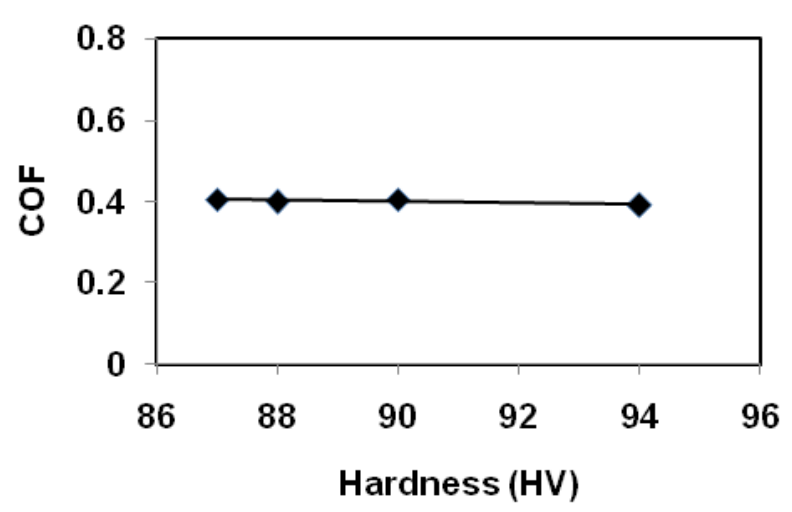

Fig-13: COF versus hardness

\section{CONCLUSIONS}

The significant findings of the present study can be summarized as follows.

- Solidification time increases as the diameter of the specimen increases keeping other parametres constant.

- Hardness of the alloy decreases with an increase in the diameter which is due to increased solidification time.

- Yield strength and tensile strength are increases with hardness.

- \% elongation decreases with an increase in hardness, YS and TS of the alloy. 
- Wear rate is inversely proportional to the hardness of the alloy as per Archard's adhesion theory of wear.

- The coefficient of friction is found to be a constant and is not a function of hardness.

\section{REFERENCES}

[1]. Gorazd Planinsic and Michael Vollmer (2008), "The surface to-volume ratio in thermal physics", European Journal of Physics, Vol 29, No 2, pp 369-384

[2]. Eman J. Abed (2011), "The influence of different casting method on solidification time and mechanical properties of AL- Sn castings", International Journal of Engineering \& Technology, Vol 11, No 6, pp 34-44.

[3]. Hurst S (1996), "Metal Casting", Intermediate Technology Publications.

[4]. Askeland R, "The Science and Engineering of Materials", 4th Edition.

[5]. Schwartz LH and Plewes JT (1974), "Spinodal Decomposition in a Cu-9 wt\% Ni-6 wt\% Sn-II, A Critical Examination of Mechanical Strength of Spinodal Alloys", Acta Metallurgica, Vol 22, No 7, pp 911-921.

[6]. Singh JB, Cai W and Bellon P (2007), "Dry sliding of $\mathrm{Cu}-15$ wt\%Ni-8 wt\%Sn bronze: Wear behaviour and microstructures", Wear, Vol 263, No(1-6), pp 830-841.

[7]. Archard JF (1953), "Contact and rubbing of flat surfaces", Journal of Applied Physics, Vol 24, No 8, pp 981988.

[8]. Zhang SZ, Jiang BH and Ding WJ (2008), "Wear of Cu15Ni-8Sn spinodal alloy", Wear, Vol 264, No (3-4), pp199203.

[9]. Zhang S, Jiang B and Ding W (2010), "Dry sliding wear of Cu-15Ni-8Sn alloy", Tribology International, Vol 43, No (1-2), pp 64-68

\section{BIOGRAPHIE:}

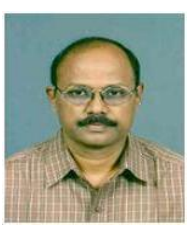

The author has completed his Bachelor's Degree in Mechanical Engineering and Master's Degree in Production Engineering. Also he has fourteen years of industrial experience and sixteen years in teaching.

Further he has completed Ph.D. in Materials Engineering. 